\title{
Editorial
}

\section{Can the Success of Primary Health Care in Sri Lanka be Maintained?} Jane Brandt Sørensen ${ }^{1,2 \unrhd}$, Flemming Konradsen ${ }^{1,2}$, Suneth Agampodi ${ }^{3}$

${ }^{1}$ Department of Public Health, University of Copenhagen, Denmark

${ }^{2}$ South Asian Clinical Toxicology Research Collaboration (SACTRC), Sri Lanka

${ }^{3}$ Department of Community Medicine, Rajarata University of Sri Lanka, Sri Lanka

\begin{abstract}
This year marks the $40^{\text {th }}$ anniversary of the Alma-Ata Declaration, adopted at the International Conference on Primary Health Care in 1978. Building upon Sri Lanka's policies of free access to government provided health care services since the 1930s, the country signed the Alma-Ata Declaration in the same year. Since then, Sri Lanka's health system has served as a role model for successful implementation of PHC for a number of years. The question is however, whether it is possible to keep this position as a PHC role model among low- and middle-income countries. We highlighted here some of those challenges and the way forward.
\end{abstract}

Key words: Alma-Ata Declaration, Primary Health Care, Sri Lanka, Non-communicable diseases

Copyright: () 2017 Sørensen et al. This is an open access article distributed under the Creative Commons Attribution License, which permits unrestricted use, distribution, and reproduction in any medium, provided the original work is properly cited.

Funding: None

Competing interest: None

$\triangle$ Correspondence: janebs@sund.ku.dk

DOI: http://doi.org/10.4038/amj.v11i1.7645

This year marks the $40^{\text {th }}$ anniversary of the Alma-Ata Declaration, adopted at the International Conference on Primary Health Care in 1978. The Declaration focused on health as 'a state of complete physical, mental and social well-being and not merely the absence of disease or infirmity' and recommended a cross-sectoral approach to promote health $(1,2)$. It highlighted the inequality of health statuses between countries as unacceptable and noted how health for all was a human right. A key element was that of Primary Health Care (PHC) and how it should be incorporated in national health systems to achieve universal health care for all (1). Currently, universal health coverage is on the agenda through the Sustainable Development Goals (SDGs), where the aim is to ensure healthy lives and promote well-being for all (3).

Building upon Sri Lanka's policies of free access to government provided health care services since the 1930s, the country signed the Alma-Ata Declaration in 1978 (2). Sri Lanka's health system has served as a role model for successful implementation of PHC for a number of years (4). Specifically, it has used community-based health services supported by the PHC system (5). For instance, Sri Lanka improved rural health centres by staffing them with competent midwives, thereby bringing health services closer to rural families and reducing the need for beds in urban referral hospitals (4). The significant focus on PHC has had a profound effect on health in the country, especially in regards to maternal and child health, immunization and control of major infectious diseases (2). Regardless of economic fluctuations, Sri Lanka has managed to maintain a satisfactory level of health (6). Life expectancy at birth has continuously risen and is currently 75 years ( 72 years for men and 78 years for women), which is considerably higher than the WHO regional average of 67 years (7). Furthermore, under-five mortality and maternal mortality has decreased significantly over the years (7).

The question is however, whether it is possible to keep this position as a PHC role model among low- and middleincome countries. Sri Lanka has one of the fastest aging populations in South Asia. It is estimated that the population over 60 will double within the next 25 years (8). This brings additional health requirements of elderly people in a system with limited social security (6) as well as decreasing family support. Such changes in the demographic composition also brings an epidemiological 
transition. Over the past decades, the relative importance of communicable, maternal and perinatal diseases have decreased and today more than $75 \%$ of deaths in Sri Lanka are caused by non-communicable diseases (NCDs) (9). Also, causes of injuries have changed with an increasing importance of traffic related injuries (7).

This epidemiological transition requires a significant transformation of the PHC system in Sri Lanka with updated health policies and services to ensure an adequate response to the new demands. A recent World Bank assessment concluded that there was no evidence yet that Sri Lanka is performing well in terms of managing NCDs, nor that the health system, as it is currently configured, is well positioned to do so. The rapid epidemiological transition further calls for educating a greater number of health professionals in established as well as new fields of professions. The current capacity at the training institutions may not be equipped to fulfil future demands. This will influence a key component of the health care system building blocks - the human resources - and are likely to affect the greatest on the rural population (10).

Expenditure on health as a share of gross domestic product (GDP) has decreased in Sri Lanka in recent years where spending on health has grown slower than the overall economy and currently stand at approximately 3\% of GDP (11). The Government spending on health has remained at around $8 \%$ of the budget for the past 10 years (11). Around the year 2006, Sri Lanka had the lowest dependency rate, which provided a window of opportunity for a favourable impact on the economy. However, Central Bank of Sri Lanka data clearly shows that Sri Lanka has not used the demographic dividend effectively (12). This missed opportunity will be an additional burden to the health care system. With the increasing pressure from the demographic and epidemiological transitions in Sri Lanka, it is questionable if government expenditure on health can be maintained at $8 \%$ without affecting universal access to health care.

Sri Lanka has a moderate incidence of catastrophic expenditure, with around $5 \%$ of the population spending more than $10 \%$ of their entire budget on health. However, high out-of-pocket expenditure (almost $40 \%$ of current health expenditure) (2) and high utilization of the private sector, even among low income groups, means that in spite of access to free state health care the actual cost of some drugs, investigations and surgeries may place a significant burden on households (13).

The ongoing epidemiological transition may without investments and health reforms result in patients, who in even greater numbers, bypass lower-level government health facilities, if not equipped to deal with the specific requirements of NCDs. Also, going forward without an intensification of government health care reforms the role of the private health care sector is likely to grow further. The private sector already plays an important role in Sri Lanka and make up approximately $55 \%$ of total spending of healthcare, especially in the context of outpatient curative care (14). According to estimations made by PricewaterhouseCoopers (PWC) out of pocket expenditure make up $86 \%$ of private expenditure on healthcare with the remainder relatively evenly split between private and employer insurance. A further move towards private care may place pressure on the households in terms of out-ofpocket payments. In addition to the growing private clinical services, the private pharmaceutic and diagnostic sectors are growing $14-17 \%$ per year (14). Clearly, the private sector offers a growing and needed service. However, the universal access have to be addressed politically to ensure an equilibrium in services and to not undermine access to health care for already marginalized urban, remote-rural and estate communities.

The need to invest in effective preventive strategies for NCDs is of paramount importance to reduce the financial burden on private households and government budgets. The current PHC system will need to incorporate such efficient preventive approaches to remain relevant. In addition to the range of important cardio-metabolic disease, mental health challenges will also have to see further investments to reduce not only individual suffering but also the tremendous burden on the society. In sum, to achieve the SDG targets for health and the aim of 'leaving no one behind', the PHC services of Sri Lanka will need to develop further in order to address the changing needs of the population.

\section{References}

1. World Health Organization member states. Declaration of Alma-Ata - International Conference on Primary Health Care, Alma-Ata, USSR, 6-12 September 1978 [Internet]. 1978. Available from: http://www.who.int/publications/almaata_declaration _en.pdf

2. Alliance for Health Policy and Systems Research, World Health Organization. Primary Health Care Systems (PRIMASYS) - Case study from Sri Lanka [Internet]. World Health Organization; 2017. Available from: http://www.who.int/alliancehpsr/projects/alliancehpsr_srilankaprimasys.pdf

3. United Nations. Sustainable Development Goals [Internet]. Sustainable Development Knowledge 
Platform. 2015. Available from: https://sustainabledevelopment.un.org/sdgs

4. Rohde J, Cousens S, Chopra M, Tangcharoensathien V, Black R, Bhutta ZA, et al. 30 years after AlmaAta: has primary health care worked in countries? The Lancet. 2008 Sep;372(9642):950-61.

5. Senanayake S, Senanayake B, Ranasinghe T, Hewageegana NSR. How to strengthen primary health care services in Sri Lanka to meet the future challenges. J Coll Community Physicians Sri Lanka. 2017 Jun 2;23(1):43.

6. Kumara AS, Samaratunge R. Patterns and determinants of out-of-pocket health care expenditure in Sri Lanka: evidence from household surveys. Health Policy Plan. 2016 Oct 1;31(8):970-83.

7. World Health Organization. Sri Lanka: WHO statistical profile [Internet]. World Health Organization; 2015. Available from: http://www.who.int/gho/countries/lka.pdf?ua=1

8. The World Bank. Sri Lanka to Improve Its Primary Healthcare Services [Internet]. The World Bank. 2018. Available from:

https://www.worldbank.org/en/news/pressrelease/2018/06/27/sri-lanka-improve-its-primaryhealthcare-services

9. World Health Organization. Sri Lanka Noncommunicable Diseases (NCD) Country Profiles , 2014 [Internet]. 2014. Available from: http://www.who.int/nmh/countries/lka_en.pdf?ua=1

10. Smith O. Sri Lanka: Achieving Pro-Poor Universal Health Coverage without Health Financing Reforms.
Washington DC: World Bank Group; 2018. Report No.: Universal Health Coverage Study Series No. 38.

11. World Health Organization, South-East Asia. Health financing profile 2017 - Sri Lanka [Internet]. 2017. Available from: http://apps.who.int/iris/bitstream/handle/10665/25964 4/HFP-SRL.pdf? sequence $=1 \&$ is Allowed $=y$

12. Central Bank of Sri Lanka. Economic and Social Statistics of Sri Lanka 2018 [Internet]. Central Bank of Sri Lanka, Statistics Department; 2018. Available from: https://www.cbsl.gov.lk/sites/default/files/cbslweb_d ocuments/statistics/otherpub/economic_and_social_st atistics_of_SL_2018_e_0.pdf

13. de Silva A, Ranasinghe T, Abeykoon P. Universal health coverage and the health Sustainable Development Goal: achievements and challenges for Sri Lanka. WHO South-East Asia J Public Health. 2016;5(2):82.

14. PricewaterhouseCoopers. The Health sector of Sri Lanka [Internet]. The Embassy of the Kingdom of the Netherlands; 2014. Available from:

https:/www.rvo.nl/sites/default/files/2016/01/Health $\% 20$ sector\%20in\%20Sri\%20Lanka.pdf 